\title{
AVALIAÇÃO DOS BANCOS DE SEMENTES DO SOLO DE FRAGMENTOS FLORESTAIS DE MATA ESTACIONAL SEMIDECIDUAL CLÍMAX E SECUNDÁRIA E SEU POTENCIAL EM RECUPERAR ÁREAS DEGRADADAS
}

\begin{abstract}
Marissol Aparecida Peres - Tecnológa em Gestão Ambiental, pós-graduanda em Auditoria e Gestão Ambiental pela Universidade Tecnológica Federal do Paraná - Campus Cornélio Procópio, marissoperes@hotmail.com. Lilian Vilela Andrade Pinto - Engenheira Florestal, D.Sc., Professora do Instituto Federal de Educação, Ciência e Tecnologia do Sul de Minas Gerais - Campus Inconfidentes, lilianvap@gmail.com.
\end{abstract}

Laércio Loures - Biólogo, M.Sc. em Manejo Ambiental.

\section{RESUMO}

O banco de sementes do solo é constituído por serrapilheira e sementes não germinadas capazes de substituir plantas que possam ter desaparecido da floresta. O objetivo deste estudo foi avaliar o banco de sementes do solo de fragmentos de floresta estacional semidecidual em diferentes estágios de sucessão e o seu potencial em recuperar áreas degradadas. A partir da coleta do banco de sementes do solo em dois fragmentos florestais de Mata Clímax e Secundária foi instalado o experimento com 4 tratamentos (Mata Clímax a pleno sol; Mata Clímax sombreada; Mata Secundária a pleno solo; Mata Secundária sombreada) utilizando 4 repetições no delineamento de blocos casualizados. A avaliação consistiu em identificar e quantificar as plântulas emergidas. Observouse que a Mata Secundária apresentou maior diversidade florística e densidade de indivíduos que a Mata Clímax, que o sombreamento mostrou efeito positivo no potencial de germinação do banco de sementes do solo das Matas Clímax e Secundária e que o banco de sementes do solo apresenta potencial em recuperar áreas degradadas.

Palavras-chave: Densidade de indivíduos; diversidade florística; grupo ecológico; porte.

\section{INTRODUÇÃO}

A serrapilheira e as sementes viáveis presentes no solo constituem o banco de sementes do solo das florestas (Simpson et al., 1989). O banco de sementes do solo é um sistema dinâmico que apresenta composição variável no espaço e no tempo, o que pode refletir na composição de uma área recém perturbada e no potencial de regeneração de uma determinada comunidade (Joly, 1986).

As sementes são adicionadas ao banco de sementes do solo continuamente através de dispersão e chuva de sementes. Essas sementes podem germinar logo após a dispersão ou entrarem em dormência e se incorporarem ao banco. O banco de sementes do solo constitue-se em sua maioria, por espécies iniciais da sucessão ecológica que apresentam sementes pequenas. Esse número de sementes pode variar de acordo com a época do ano (Santos, 2000).

$\mathrm{O}$ banco de sementes do solo de uma floresta representa o estoque de sementes não germinadas que quando as condições favoráveis se apresentam são capazes de substituir as plantas que eventualmente tenham desaparecido do ecossistema (Souza et al., 2006). A recuperação de ecossistemas degradados é uma atividade muito antiga, podendo-se encontrar exemplos de sua existência na história de diferentes povos, épocas e regiões. No entanto, até recentemente, ela se caracterizava como uma atividade sem vínculos estreitos com concepções teóricas, sendo executada normalmente como uma prática de plantio de mudas, com objetivos muito específicos (Rodrigues \& Gandolfi, 2004). 
O uso do banco de sementes do solo é útil na recuperação de áreas degradadas e apresenta como principal vantagem à possibilidade de restabelecer no local degradado um ecossistema que se assemelha, pelas espécies contidas, aquele que existia antes da perturbação. Para poder tornar o processo de revegetação mais barato e eficiente, o banco de sementes pode ser retirado de fragmentos próximos ou até mesmo da área a ser impactada. Os custos de recuperação de áreas degradadas, através do reflorestamento com espécies nativas, variam significativamente em função das características da área a ser recuperada. Assim, nas áreas de empréstimo, os serviços de regularização do terreno para plantio de mudas, encarecem a operação em mais de três vezes (Galli \& Gonçalves, 2000), podendo, portanto, o uso do banco de sementes do solo ser uma alternativa interessante.

O sucesso do uso do banco de sementes em áreas impactadas depende das espécies presentes no banco de sementes do solo, da capacidade de germinação dessas sementes e do seu potencial de estabelecimento (Souza et al., 2006).

O banco de sementes no solo, exerce papel fundamental no processo de sucessão secundária, uma vez que possibilita o início da regeneração das espécies em áreas que tenham sofrido distúrbios. As espécies pioneiras, que em sua maioria apresentam mecanismos de dormência de sementes, são as mais freqüentes na composição dos bancos de sementes em florestas tropicais. Portanto, a auto-renovação de florestas tropicais é assegurada pela existência de um banco de sementes no solo, compostos por um determinado número de espécies pioneiras, e o potencial de recuperação de áreas degradadas podem ser avaliados através do estudo do banco de sementes (Schimitz, 1992).

Assim, o presente estudo teve como objetivos: (i) avaliar o banco de sementes do solo de fragmentos de floresta estacional se- midecidual em diferentes estágios de sucessão e o seu potencial em recuperar áreas degradadas; (ii) comparar a diversidade e a densidade de indivíduos dos bancos de sementes do solo dos fragmentos de floresta estacional semidecidual Clímax e Secundária; (iii) avaliar se o sombreamento afeta o potencial de germinação do banco de sementes do solo das florestas estacional semidecidual Clímax e Secundária.

\section{MATERIAL E MÉTODOS}

A coleta da serrapilheira foi realizada em dois fragmentos de floresta estacional semidecidual que encontram-se em estágio clímax e secundário de regeneração, localizados no município de Inconfidentes no Sul de

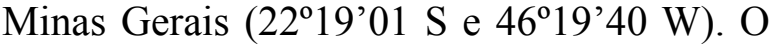
clima da região, segundo classificação de Koppen, é do tipo Cwa, tropical úmido, com precipitação pluviométrica média anual de 1500 mm e temperatura média de $19^{\circ} \mathrm{C}$.

A serrapilheira foi coletada, em abril de 2007, de forma aleatória em 64 pontos em cada fragmento com o auxílio de um enxadão e de um esquadro de madeira de $25 \mathrm{~cm} \times 25 \mathrm{~cm}$ x $10 \mathrm{~cm}$, colocado a uma profundidade de 10 $\mathrm{cm}$. A serrapilheira foi armazenada em sacos de ração até a implantação do experimento no dia 16 de abril de 2007 na fazenda do Instituto Federal de Educação, Ciência e Tecnologia do Sul de Minas Gerais - Campus Inconfidentes, próximo a Olericultura.

Uma camada de $8 \mathrm{~cm}$ de serrapilheira foi colocada dentro de esquadros de madeira $(70 \mathrm{~cm} \times 70 \mathrm{~cm} \times 10 \mathrm{~cm}$ ) forrados com lona preta. Foram simuladas duas condições de ambiente: Luz e Sombra, irrigados três vezes por semana. No tratamento com sombra foi usado sombrite $50 \%$ e no tratamento com luz, a camada de serrapilheira ficou exposta ao sol. $\mathrm{O}$ experimento foi instalado no delineamento experimental em blocos casualizados - DBC, totalizando 4 tratamentos (Mata Clímax com luz, Mata Clímax com sombra, Mata Secun- 
dária com luz e Mata Secundária com sombra) com 4 repetições.

As avaliações realizadas foram à quantificação e identificação das plântulas. A primeira quantificação das plântulas foi feita no dia 18 de abril de 2007. Foram feitas quantificações semanais a partir dessa dada até o dia 30 de maio e a partir daí foram feitas quantificações quinzenais até o dia 31 de outubro de 2007, totalizando 18 contagens. A identificação das plântulas iniciou-se a partir do momento em que as mesmas atingiram um estádio passível de identificação a olho nu.

Para descrever a estrutura do banco sementes do solo foi estimado, para todas as espécies amostradas, o seguinte parâmetro fitossociológico clássico de Mueller-Combois \& Ellenberg (1974): densidade absoluta (a qual indica o número total de indivíduos de uma determinada espécie por unidade de área). Os cálculos foram processados com auxílio do programa Excel, utilizando a seguinte expressão:

$$
D A_{i}=\frac{N_{i}}{A} \text { em que: }
$$

$\mathrm{Ni}=$ número de indivíduos da espécie $\mathrm{i}$;

$\mathrm{A}=$ área amostral em ha;

Para estimar a diversidade florística das Mata Clímax e Secundária foi utilizado o índice de Shannon-Weaver (H') e de equabilidade de Pielou (J'). Este índice é calculado com base na relação entre o número de indivíduos de cada espécie e o número total de indivíduos amostrados por intermédio das seguintes expressões:

$$
H^{\prime \prime}=-\sum_{i=1}^{S} \frac{n i}{N} * \ln \frac{n i}{N} \text { em que: }
$$

H'= Índice Shannon-Weaver;

In $=1 \ldots$;

$\mathrm{s}=$ número de espécie de espécies vivas amos-

tradas;

ni = número de indivíduos da espécie $\mathrm{i}$;
$\mathrm{N}$ = número total de indivíduos amostrados; e $\ln =$ logaritmo neperiano

O índice de equabilidade de Pielou (J') foi calculado a partir da seguinte expressão:

$$
J^{\prime}=\frac{H^{\prime}}{H \max } \quad \text { onde: }
$$

$\mathrm{H}^{\prime}=$ índice de Shannon-Weaver;

Hmax (diversidade máxima $)=\ln \mathrm{s}$, sendo s o número de espécies.

\section{RESULTADOS E DISCUSSÕES}

Durante os primeiros 100 dias de experimentação não verificou-se diferenciação significativa na emergência das plântulas das diferentes Matas (Clímax e Secundária) e das diferentes condições ambientais (pleno sol e sombreamento). Após 114 dias do início do experimento, a emergência de plântulas da Mata Secundária sombreada se sobressaiu estatisticamente em relação a emergência de plântulas dos outros tratamentos avaliados. Tanto no experimento da Mata Secundária quanto da Mata Clímax, o sombreamento propiciou maior emergência das plântulas quando comparado com os experimentos a pleno sol (Figura 1).

De acordo com Souza et al. (2006) a mata em estádio médio de sucessão (Secundária) e estádio jovem (capoeira) é composta principalmente por espécies pioneiras e secundárias iniciais (clímax exigentes de luz). As espécies pioneiras apresentam como característica a produção de grande número de sementes ortodoxas, que podem apresentar dormência e consequentemente enriquecerem o banco de sementes do local.

O banco de sementes do solo da Mata Secundária tanto sob a condição a pleno sol quanto sob sombreamento apresentou maior número de indivíduos, espécies e famílias, quando comparado com o banco de sementes do solo da Mata Clímax sob as duas condições 
de ambiente, luz e sombra (Tabela 1). Segundo Caldato et al. (1996) florestas que raramente sofrem perturbações tendem a ter densidades mais baixas em seu banco de sementes.

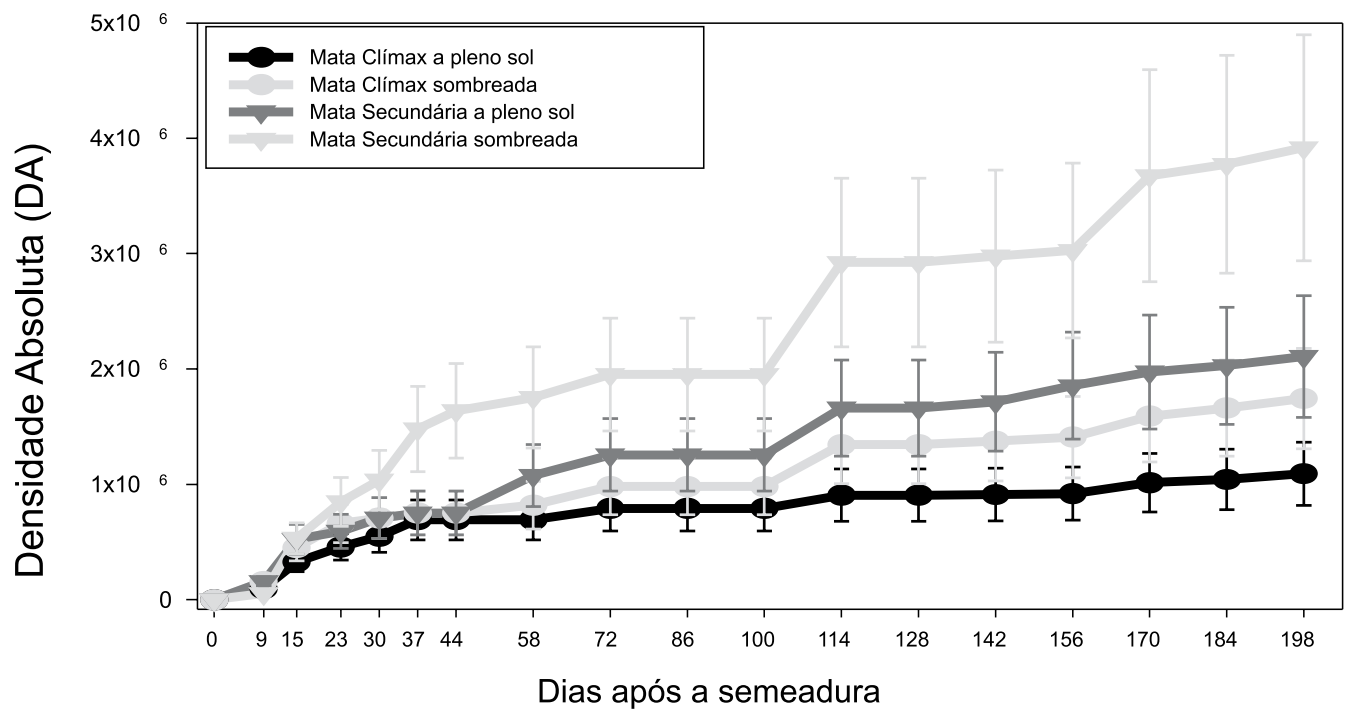

Figura 1. Densidade absoluta de plântulas contidas no banco de sementes do solo de fragmentos de mata Clímax e Secundária, a pleno sol e sombreadas, durante 198 dias. Pontos representam a média da densidade absoluta da emergência das plântulas e as barras os desvios padrões de 4 repetições.

O tratamento que apresentou maior número de famílias foi o de Mata Secundária sombreada, com 32 famílias (Tabela 1). As famílias que estiveram presentes em todos os tratamentos foram Amaranthaceae, Asteraceae, Cannabaceae, Euphorbiaceae, Loganiaceae, Malvaceae, Oxolidaceae, Piperaceae, Poaceae, Rosaceae, Rubiaceae, Salicaceae, Solanaceae e Urticaceae, totalizando 14 famílias (Tabela 2). As famílias Annonaceae, Convolvulaceae, Erythoxylaceae, Marantaceae, Myrsinaceae e Myetaceae, estiveram presentes em apenas um dos tratamentos (Tabela 2).

A densidade de indivíduos na Mata Secundária é maior que na Mata Clímax (Tabela 1) indo ao encontro dos resultados de Quanz (2006) que ao estudar o banco de sementes do solo de florestas primárias e de florestas secundárias em diferentes idades verificou que a densidade do banco de sementes da floresta primária é menor que a densidade da floresta secundária.

Os valores dos índices de diversidade de Shannon-Weaver (H') calculado para o banco de sementes do solo dos tratamentos de
Mata Clímax a pleno sol, Mata Clímax sombreada, Mata Secundária a pleno sol e Mata Secundária sombreada foram, respectivamente, de 3,32348; 3,42857; 3,077; 3,06929 e de equabilidade de Pielou ( $\mathrm{J}$ '), 0,56357; 0,5403; 0,$46269 ; 0,41595$, respectivamente (Tabela 1). Segundo Almeida Júnior (1999) em florestas tropicais os valores do índice de Shannon-Weaver tende a aumentar na medida em que a vegetação se aproxima do estádio clímax. Assim, os maiores valores do índice de diversidade de Shannon-Weaver (H') encontrado para os tratamentos de Mata Clímax a pleno sol e sombreada possibilita inferir que a classificação das Matas em clímax e secundária dada antes das análises foi coerente. Pinto et al. (2005), em seu estudo sobre nascentes, classificou uma área como sendo perturbada a que apresentava menor índice de Shannon-Weaver, concordando com o resultado de que a Mata Secundária apresenta interferência antrópica.

Os baixos valores do índice de equabilidade de Pielou encontrado nas Matas Clímax e Secundária possibilita inferir que há uma dominância ecológica mais pronunciada de 
alguma espécie que, predomina na comunidade destas Matas, ou seja, uma maior concentração de indivíduos de espécies dominantes. No tratamento de Mata Clímax a pleno sol as espécies que apresentaram maior porcentagem de indivíduos foram a Solanum americanum e Sonchus ciliatus com 14,8\% e 13,9\%, respectivamente, de um total de 46 espécies. Dentre as 47 espécies presentes no banco de sementes da Mata Clímax sombreada, as espécies com maior densidade foram Photho- morphe umbellata $(9,9 \%)$, S. ciliatus $(8,8 \%)$ e Cecropia graziovii $(8,4 \%)$. O tratamento de Mata Secundária a pleno sol apresentou 54 espécies das quais as que apresentaram maior porcentagem de indivíduos foram: gramínea não identificada $(18,2 \%)$, Centella asiática $(16,1 \%)$ e Baccharis dracunculifolia (14,7\%). Já no tratamento de Mata Secundária sombreada das 56 espécies as mais abundantes foram P. umbellata $(19,4 \%)$ e gramínea não identificada $(16,8 \%)$.

Tabela 1. Parâmetros quantitativos da vegetação apresentados nos tratamentos: Mata Clímax a pleno sol; Mata Clímax sombreada; Mata Secundária a pleno sol e Mata Secundária sombreada. N = número de indivíduos; $\mathrm{DAT}=$ densidade absoluta total; $\mathrm{E}=$ número de espécies amostradas; $\mathrm{F}=$ número de família amostradas; H' = índice de diversidade de Shannon-Weaver (H'); e J' = índice de equabilidade de Pielou (J').

\begin{tabular}{lcccccc}
\hline TRATAMENTO & N & DAT & E & F & H' & J' \\
\hline Mata Clímax a pleno sol & 360 & 1693903 & 46 & 22 & 3,32348 & 0,56357 \\
Mata Clímax sombreada & 570 & 2899051 & 47 & 28 & 3,42857 & 0,5403 \\
Mata Secundária a pleno sol & 773 & 3653349 & 54 & 29 & 3,077 & 0,46269 \\
Mata Secundária sombreada & 1602 & 8102021 & 56 & 32 & 3,06929 & 0,41595 \\
\hline
\end{tabular}

As espécies pioneiras representaram 90,3\% e as espécies clímax 9,7\% em média em todos os tratamentos, estando às espécies clímax presentes nos tratamentos de Mata clímax, exceto a Zanthoxlum rhoifolium, presente no tratamento Mata Secundária a pleno sol. A Mata Clímax a pleno sol apresentou $87,5 \%$ de espécies pioneiras e $12,5 \%$ de espécies clímax e a Mata Clímax sombreada apresentou $85,71 \%$ e $14,29 \%$ de espécies pioneiras e clímax, respectivamente (Figura 2). A Mata Secundária a pleno sol apresentou 94,44\% e $5,56 \%$ de espécies pioneiras e clímax, respectivamente, e a Mata Secundária sombreada apresentou $100 \%$ de espécies pioneiras (Figura 2). Segundo Garwood (1989) citado por Scherer e Jarenkow (2006), espécies pioneiras podem representar entre $18 \%$ e $90 \%$ do total de espécies encontradas nos bancos de sementes do solo. Lopes et al. (2001) encontraram um total de $91,7 \%$ de espécies pioneiras, $1,7 \%$ de espécies clímax e $6,6 \%$ não foram relatadas pelos autores.

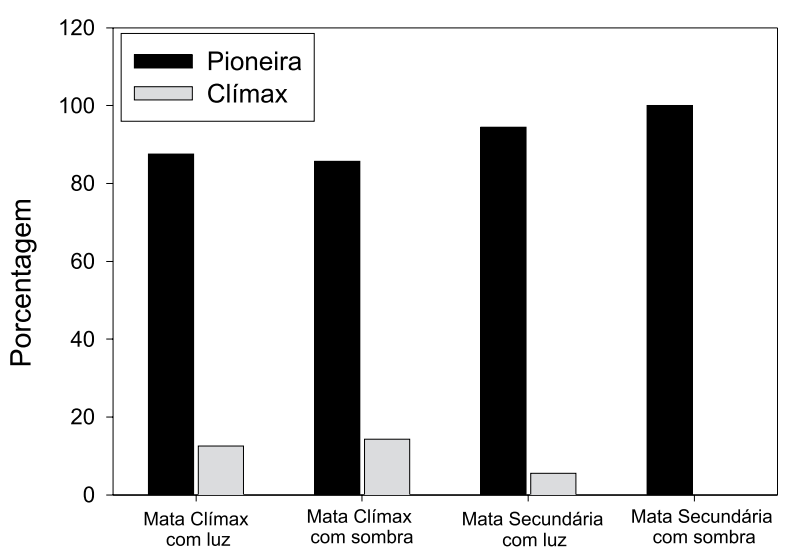

Figura 2. Grupo ecológico das espécies em percentagem das Matas Clímax e Secundária, a pleno sol e sombreada.

Nos tratamentos avaliados observouse presença elevada de espécies herbáceas $(68,24 \%)$. Nos tratamentos de Mata Clímax a pleno sol, Mata Clímax sombreada, Mata Secundária a pleno sol e Mata Secundária sombreada o percentual de herbáceas foi respectivamente de 55,56\%; 58,62\%; 44,45\% e $66,09 \%$ (Figura 3). Souza et al. (2006), em seu 


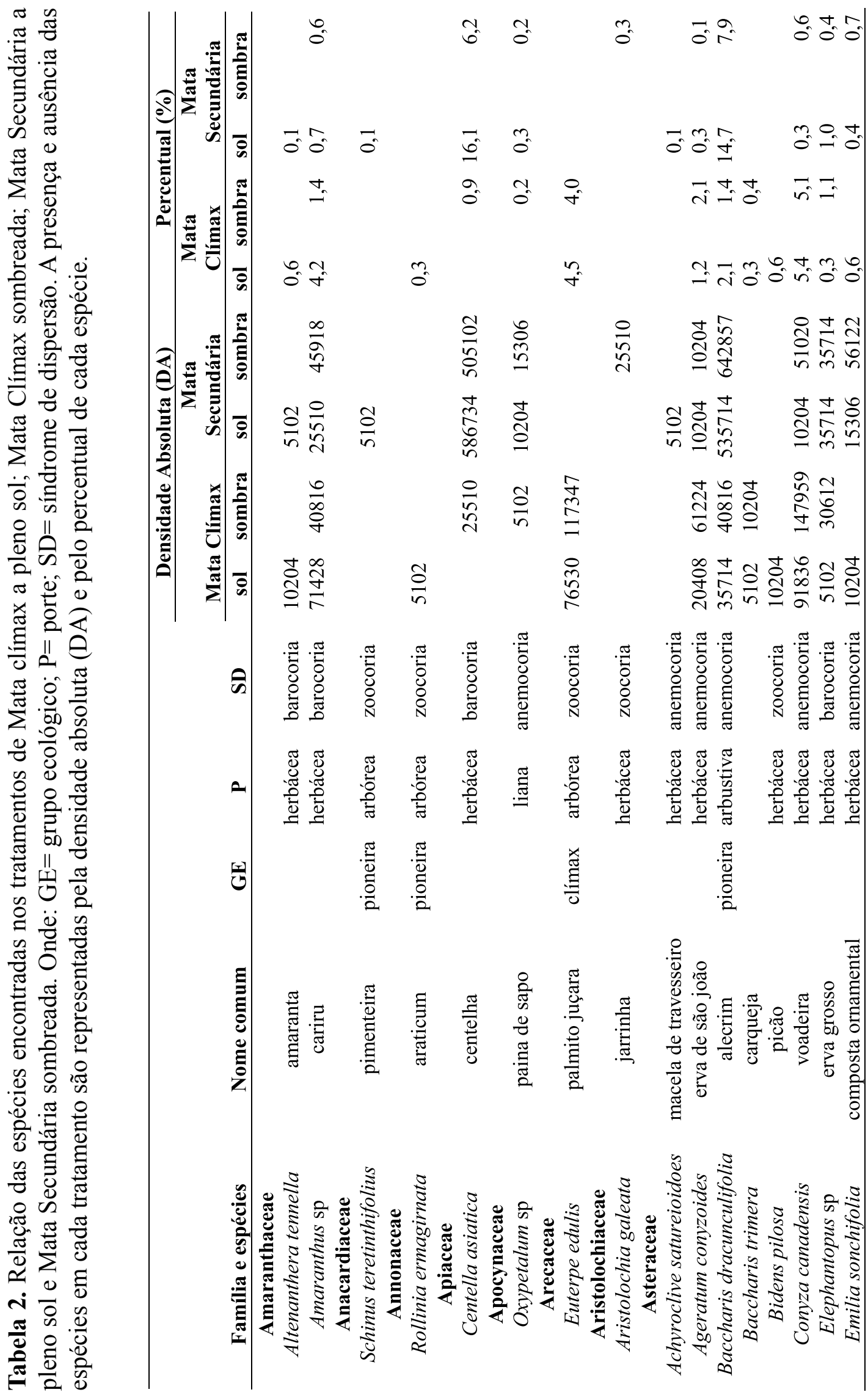




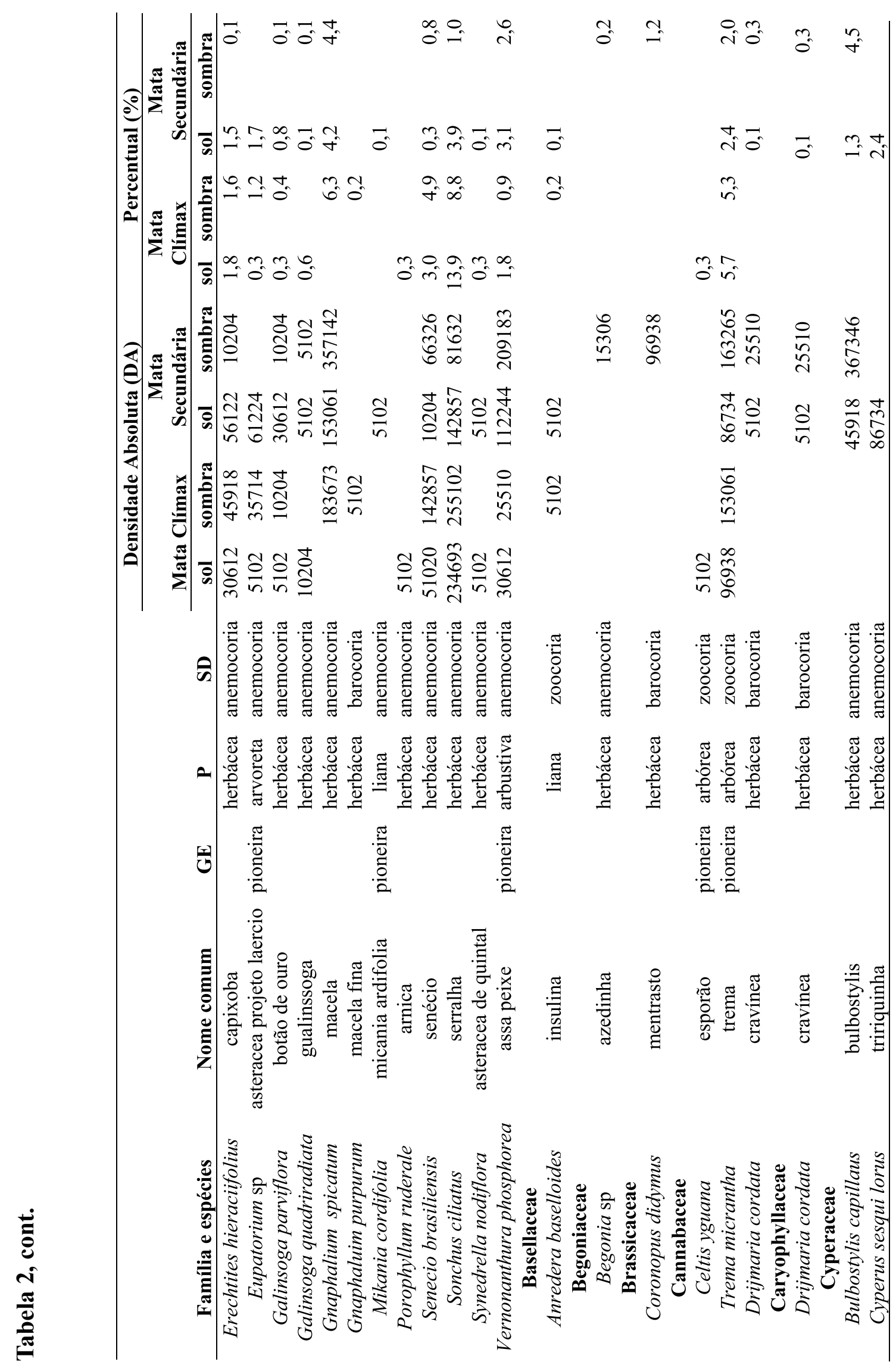




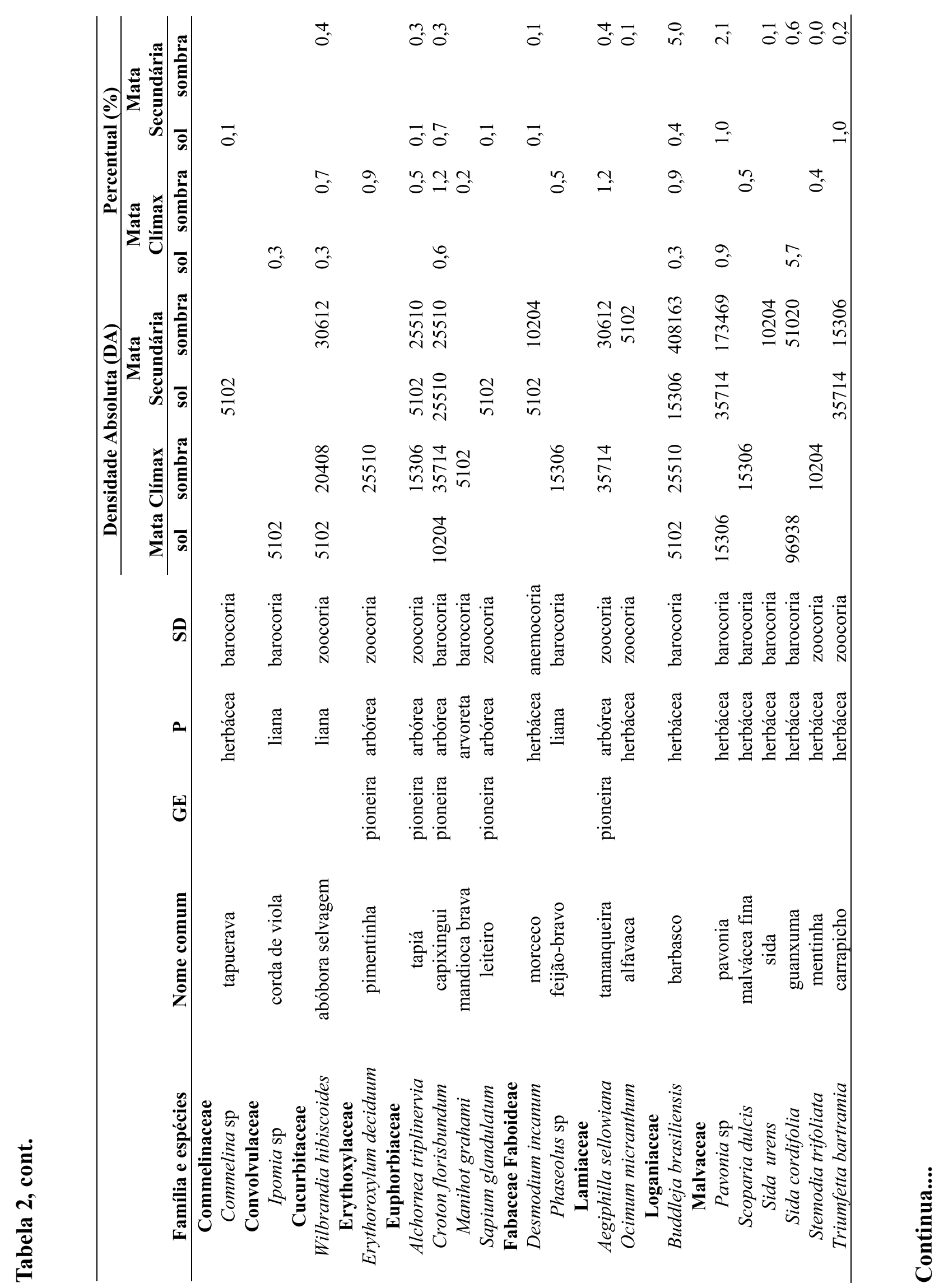




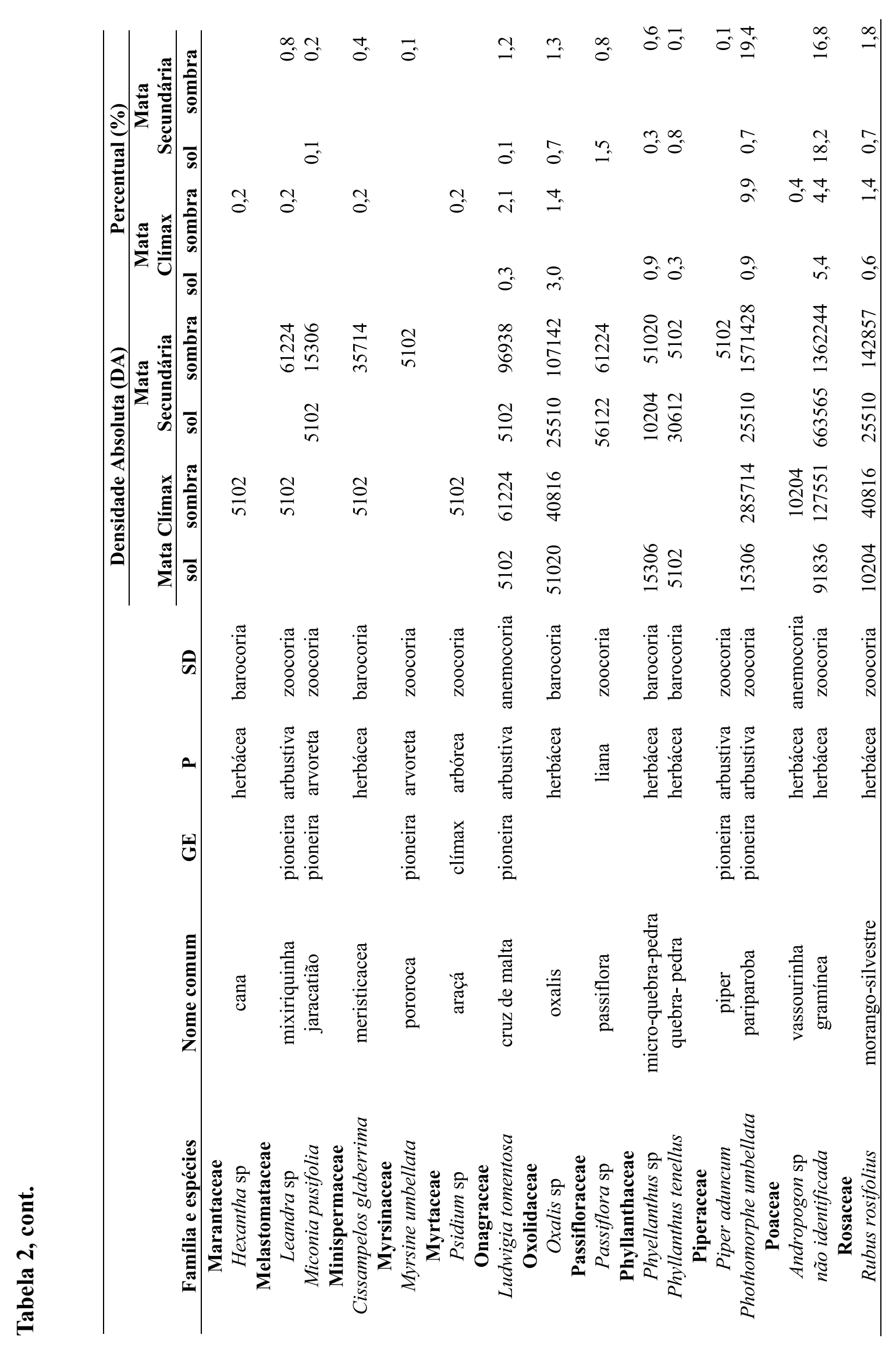




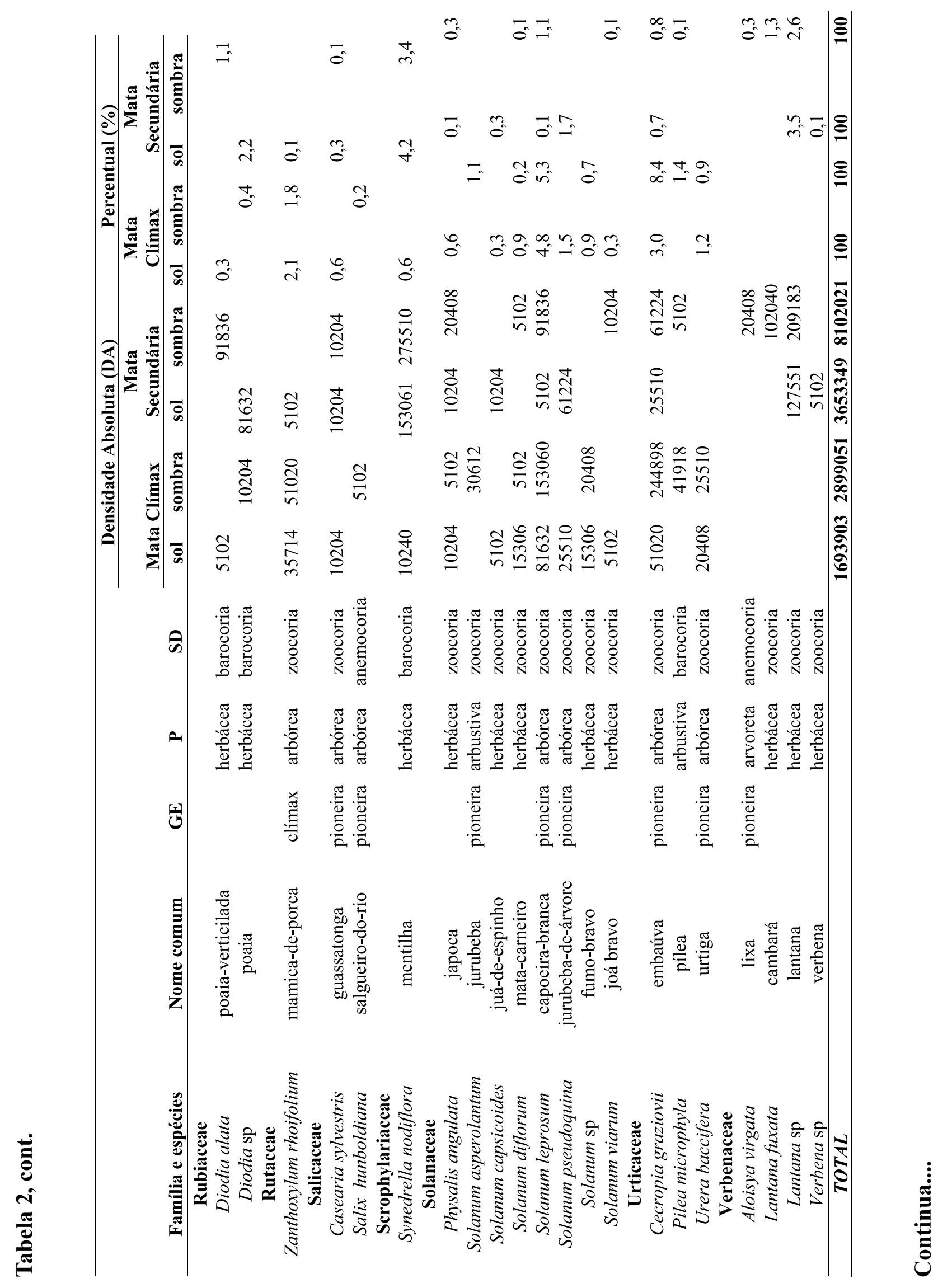




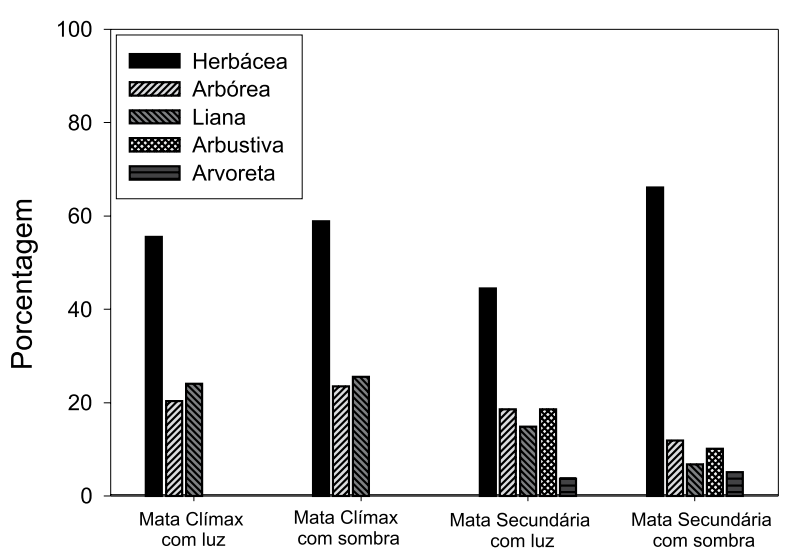

Figura 3. Porte das espécies em percentagem das Matas Clímax e Secundária, a pleno sol e sombreada.

estudo sobre banco de sementes contidos em serrapilheira, relatou que a grande quantidade de sementes de espécies herbáceas encontradas pode estar relacionada com o ciclo de vida dessas espécies, a produtividade de sementes, a ausência ou não continuidade do dossel, que facilitaria a entrada de suas sementes e sua incorporação no solo. Segundo Maciel et al. (2003) as sementes de espécies pioneiras só germinam recebendo radiação solar em pelo menos parte do dia.

Os tratamentos de Mata Secundária apresentaram espécies de portes menores, como arbustos, arvoretas e lianas. As lianas estiveram presentes em todos os tratamentos, sendo, respectivamente, $24,07 \%$ e $25,49 \%$, nos tratamentos de Mata Clímax a pleno sol e sombreada; $14,81 \%$ e $6,8 \%$, nos tratamentos de Mata Secundária a pleno sol e sombreada (Figura 3). As espécies arbustivas nos tratamentos de Mata Secundária a pleno sol e Mata Secundária sombreada apresentaram o percentual, respectivamente de 18,52 e 10,17\% (Figura 3). Isso já era esperado, pois a Mata Secundária encontra-se em estádio de regeneração, não tendo espécies muito desenvolvidas. Já as arvoretas estão presentes somente nos tratamentos de Mata Secundárias, isso provavelmente seja devido ao estádio de regeneração da Mata. O percentual das arvoretas nos tratamentos é de 3,7\% na Mata Secundária a pleno sol e 5,8\% na Mata Secundária sombreada (Figura 3).

A média de herbáceas nos quatro tratamentos foi de 56,18\%. Lopes et al. (2006), estudando o banco de sementes de sub-bosques de povoamentos florestais também observou a predominância de espécies herbáceas, seguida da arbustiva e arbórea, na maioria das áreas estudadas. Péllico Netto et al. (2003) em seu estudo sobre caracterização do banco de sementes do solo de uma floresta estacional semidecidual em Cássia, MG, observou que as espécies pioneiras de menor porte, representada por herbáceas e cipós apresentam maior porcentagem (78\%) e as arbóreo-arbustivas representaram $22 \%$ do total de plântulas emergidas.

A porcentagem de espécies arbóreas encontradas por tratamentos foi de $24,14 \%$ na Mata Clímax a pleno sol; 26,42\% na Mata Clímax sombreada; $14,42 \%$ na Mata Secundária a pleno sol e 14,04\% na Mata Secundária sombreada (Figura 3). Nota-se que a Mata Clímax apresenta maior percentual de espécies arbóreas, isso já era esperado, pois esta apresenta espécies com dossel desenvolvido. As espécies arbóreas com maior densidade de indivíduos foram a Trema micranta e Cecropia graziovii, tanto na Mata Clímax como na Mata Secundária. Scherer \& Jarenkow (2006) em seu estudo sobre banco de sementes notaram que entre as espécies pioneiras, T. micrantha apresentou maior número de indivíduos na amostragem total após a germinação.

No tratamento de Mata Clímax a pleno sol a zoocoria $(46,30 \%)$ foi a síndrome de dispersão mais freqüente entre as espécies, seguida por barocoria $(27,78 \%)$ e anemocoria $(25,93 \%)$ (Figura 4). Na Mata Clímax sombreada a zoocoria, barocoria e anemocoria representaram respectivamente, 45,10\%; 27,45\% e $27,45 \%$ (Figura 4). Os tratamentos de Mata Secundária a pleno sol e sombreada apresentaram respectivamente, $38,46 \%$ e $43,10 \%$ 
das sementes com síndrome de dispersão por zoocoria; $38,46 \%$ e $31,03 \%$ por anemocoria e $23,08 \%$ e $25,86 \%$ por barocoria (Figura 4 ).

Nos quatro tratamentos a síndrome de dispersão predominante foi a zoocoria. Segundo Macedo (1993) as espécies pioneiras produzem precocemente muitas sementes pequenas, normalmente com dormência, as quais são predominantemente dispersadas por animais. Diferentemente do que foi relatado por Faria Júnior e Santos (2006) em seu estudo no Parque Estadual da Serra dos Pirineus, Goiás, o quais observaram que a síndrome de dispersão mais freqüente foi a anemocoria com $57 \%$ das espécies, seguida da zoocoria com $22 \%$ e autocoria com $21 \%$. Araújo et al. (2005) apresentou em seu estudo sobre florística da vegetação arbustivo-arbórea colonizadora de uma área degradada por mineração, que a principal síndrome de dispersão é a zoocórica, com mais de $60 \%$ das espécies, anemocóricas 33\% e autocóricas ou desconhecidas 7\%.

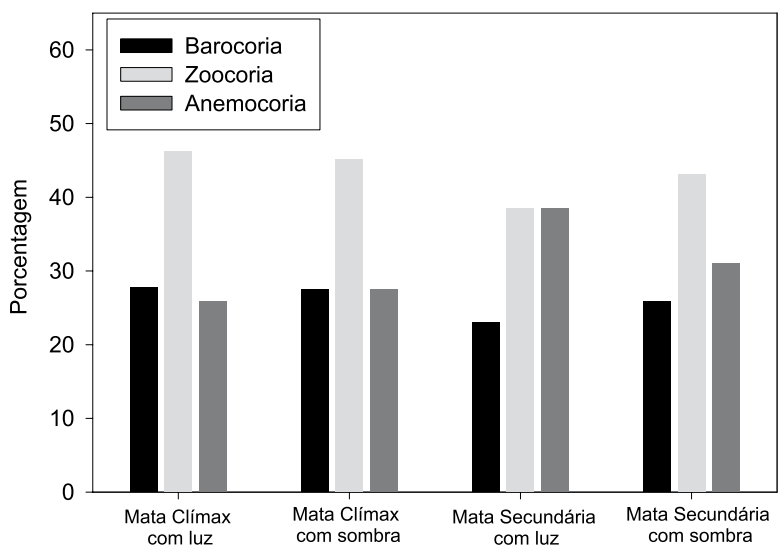

Figura 4. Síndrome de dispersão das espécies em percentagem das Matas Clímax e Secundária, a pleno sol e sombreada.

\section{CONCLUSÕES}

Os bancos de sementes do solo de fragmentos florestais de mata estacional semidecidual Clímax e Secundária demonstraram que tem potencial em recuperar áreas degradadas.
A mata estacional semidecidual Secundária apresentou maior diversidade florística e maior densidade de indivíduos que a mata estacional semidecidual Clímax.

O sombreamento mostrou efeito positivo no potencial de germinação do banco de sementes do solo das florestas estacional semidecidual Clímax e Secundária.

\section{REFERÊNCIAS BIBLIOGRÁFICAS}

\begin{abstract}
ALMEIDA JÚNIOR, J. S. Florística e Fitossociologia de fragmentos da floresta estacional semidecidual, Viçosa, Minas Gerais. 1999. 148p. Dissertação (Mestrado em Ciências Florestais). Universidade Federal de Viçosa. Viçosa, MG.
\end{abstract}

ARAÚJO, F. S.; MARTINS, S. V.; MEIRA NETO, J. A. A.; LANI, J. L.; PIRES, I. E. Florística da vegetação arbustivo-arbórea colonizadora de uma área degradada por mineração de Caulim, em Brás Pires, MG. Revista Árvore, Viçosa - MG. v. 29, n. 6. p. 983-992. 2005.

CALDATO, S. L.; FLOSS, P. A.; CROCE, D. M. da; LONGHI, S. J. Estudo da regeneração natural, banco de sementes e chuva de sementes na Reserva Genética Florestal de Caçador, SC. Ciência Florestal, Santa Maria, v.6, n.1, p.27-38 27. 1996.

FARIA JÚNIOR, J. E. Q.; SANTOS, M.L. Recursos Florais e Síndrome de polinização de espécies de Campo Rupestre no Parque Estadual da Serra dos Pireneus, Goiás. IV Seminário de Iniciação Cientifica. Universidade Estadual de Goiás. Anápolis, Goiás. 2006. 7p.

GALLI, L. F.; GONÇALVES, J. C. Recuperação de Áreas Degradadas da Mata Atlântica. Uma experiência da CESP. Companhia Energética de São Paulo. Caderno 3. $2^{\mathrm{a}}$ edição. São Paulo, SP. 2000. 26p. 
JOLY, C. A. Heterogeneidade ambiental e diversidade de estratégias adaptativas de espécies de mata de galeria. In: Simpósio da Academia de Ciências de São Paulo - Perspectivas de Ecologia Teórica, 1986, São Paulo. Anais... São Paulo: ACIESP, 1986. p.19-38.

LOPES, J. C. A.; WHITMOORE, T. C.; BROW, N. D.; JENNINGS, S. B. 2001. Banco de sementes de uma floresta tropical úmida no município de Moju, PA. In: SILVA, J. N. M.; CARVALHO, J. O. P.; YARED, J. A. G. (Eds). A silvicultura na Amazônia Oriental: contribuições do projeto Embrapa/DFID. Belém: Embrapa Amazônia Oriental, DFID, 2001. p. 185-201.

LOPES, K.P.; SOUZA, V.C.; ANDARDE, L. A.; DORNELAS, G. V.; BRUNO, R. L. A. Estudo do banco de sementes em povoamentos florestais puros e em uma capoeira de Floresta Ombrófila Aberta, no município de Areia, PB, Brasil. Acta Botânica Brasileira, v.20, n.1, p.105-113, 2006.

MACEDO, A. C. Revegetação Matas Ciliares e de Proteção Ambiental. Governo do Estado de São Paulo. Fundação Florestal. São Paulo. 1993. 24 p.

MACIEL, M. N. M.; WATZLAWICK, L. F.; SHOENINGER, E. R.; YAMAJI, F. M. Classificação ecológica das espécies arbóreas. Revista Acadêmica: ciências agrárias e ambientais. Curitiba, v.1, n.2, p. 69-78, abr.jun. 2003.

MULLER-COMBIS, D.; ELLENBERG, M. Aims and methods of vegetation ecology. New York: John Wiley \& Sons, 1974. 547p.

PÉLLICO NETTO, S.; ROGOLIM - SÁ, O.; COSTA, E. B.; MORAIS, A. S. Caracterização do banco de sementes no solo de uma floresta no município de Cássia, MG. 2003. p.1-4.

PINTO, L. V. A.; BOTELHO, S.A.; OLIVEIRA FILHO, A. T.; DAVIDE, A. C. Estudo da vege- tação como subsídios para propostas de recuperação das nascentes da Bacia Hidrográfica do Ribeirão Santa Cruz, Lavras, MG. Revista Árvore, Viçosa-MG, v.29, n.5, p.775-793, 2005.

QUANZ, B. Banco de sementes do solo de uma floresta de terra firme na Fazenda Rio Capim, Paragominas - PA, aos 13 meses após exploração de um impacto reduzido. Belém, PA. 2006. Dissertação (mestrado). Universidade Federal Rural da Amazônia. p.68.

RODRIGUES, R.R.; GANDOLFI, S. Conceitos, tendências e ações para a recuperação de Florestas Ciliares, p.235-247. In: RODRIGUES, R.R.; LEITÃO FILHO, H.F. Matas Ciliares: Conservação e Recuperação. EDUSP/FAPESP 3. 2004.

SANTOS, S. L. Influência da serrapilheira na germinação e desenvolvimento de plântulas da Mata de Santa Genebra. 2000. 71p. Tese (Mestrado em Biologia Vegetal). Universidade Estadual de Campinas. Campinas, SP.

SCHERER, C.; JARENKOW, J. A. Banco de sementes de espécies arbóreas em floresta estacional no Rio Grande do Sul, Brasil. Revista Brasileira de Botânica, v.29, n.1, p.67-77, jan.-mar. 2006.

SCHIMITZ, M. C. Recomposição da vegetação com espécies arbórea nativas em Reservatórios de Usinas Hidrelétricas da CESP. IPEF Série Técnica, Piracicaba, v.8, n.25, p. 1-43, 1992.

SIMPSON, R. L.; LECK, M. A.; PARKER, V. T. Seed banks: general concepts and methodological issues. In: LECK, M. A.; PARKER, V. T.; SIPMSON, R. L. (Eds.). Ecology of soil seed banks. London: Academic, 1989. p. 3-8.

SOUZA, P. A.; VENTURIN, N. ; GRIFFITH, J. J.; MARTINS, S. V. Avaliação do banco de sementes contido na serrapilheira de um fragmento florestal visando recuperação de áreas degradadas. Revista Cerne, Lavras, v.2, n.1, p.56-67, 2006. 